\title{
Use of an open-tubular trapping column as phase-switching interface in on-line coupled reversed-phase liquid chromatography-capillary gas chromatography
}

\author{
Citation for published version (APA): \\ Mol, J. G. J., Staniewski, J., Janssen, J. G. M., Cramers, C. A., Ghijsen, R. T., \& Brinkman, U. A. T. (1992). Use \\ of an open-tubular trapping column as phase-switching interface in on-line coupled reversed-phase liquid \\ chromatography-capillary gas chromatography. Journal of Chromatography, 630(1-2), 201-212. \\ https://doi.org/10.1016/0021-9673(93)80457-J
}

DOI:

10.1016/0021-9673(93)80457-J

Document status and date:

Published: 01/01/1992

\section{Document Version:}

Publisher's PDF, also known as Version of Record (includes final page, issue and volume numbers)

\section{Please check the document version of this publication:}

- A submitted manuscript is the version of the article upon submission and before peer-review. There can be important differences between the submitted version and the official published version of record. People interested in the research are advised to contact the author for the final version of the publication, or visit the DOI to the publisher's website.

- The final author version and the galley proof are versions of the publication after peer review.

- The final published version features the final layout of the paper including the volume, issue and page numbers.

Link to publication

\footnotetext{
General rights

- You may freely distribute the URL identifying the publication in the public portal. follow below link for the End User Agreement:

www.tue.nl/taverne

\section{Take down policy}

If you believe that this document breaches copyright please contact us at:

openaccess@tue.nl

providing details and we will investigate your claim.
}

Copyright and moral rights for the publications made accessible in the public portal are retained by the authors and/or other copyright owners and it is a condition of accessing publications that users recognise and abide by the legal requirements associated with these rights.

- Users may download and print one copy of any publication from the public portal for the purpose of private study or research.

- You may not further distribute the material or use it for any profit-making activity or commercial gain

If the publication is distributed under the terms of Article $25 \mathrm{fa}$ of the Dutch Copyright Act, indicated by the "Taverne" license above, please 


\title{
Use of an open-tubular trapping column as phase- switching interface in on-line coupled reversed-phase liquid chromatography-capillary gas chromatography*
}

\author{
Hans G. J. Mol, Jacek Staniewski, Hans-Gerd Janssen and Care1 A. Cramers \\ Faculty of Chemical Engineering, Laboratory of Instrumental Analysis, Eindhoven University of Technology, P.0. Box 513. 5600 MB \\ Eindhoven (Netherlands)
}

\author{
Rudy T. Ghijsen and Udo A. Th. Brinkman \\ Department of Analytical Chemistry, Free University, De Boelelaan 1083. 1081 HV Amsterdam (Netherlands)
}

(First received September 8th, 1992; revised manuscript received October 12th, 1992)

\begin{abstract}
The applicability of open-tubular traps for phase switching in coupled RPLC-GC was studied. The phase-switching process involves sorption of the analytes of interest from a methanol-water mobile phase into the stationary phase of an open-tubular column, removal of the aqueous phase by purging the trap with nitrogen and desorption of the analytes with hexane. Water elimination carried out in this manner appears to be highly efficient. In the sorption step the sampling flow-rate and the capacity factors of the analytes in the trap are critical parameters. Using a $2 \mathrm{~m} \times 0.32 \mathrm{~mm}$ I.D. trap with a swollen $5-\mu \mathrm{m}$ stationary phase at flow-rates not exceeding $100 \mu \mathrm{l} / \mathrm{min}$, polycyclic aromatic hydrocarbons are trapped quantitatively from $300 \mu \mathrm{l}$ of aqueous phases containing up to $65 \%$ (v/v) of methanol. For desorption $70-125 \mu \mathrm{l}$ of hexane are needed. These volumes are easy to handle in solvent elimination carried out using a PTV injector prior to transfer of the analytes to a GC column.
\end{abstract}

\section{INTRODUCTION}

The main issue in on-line coupled LC-GC currently is the coupling of reversed-phase LC (RPLC) with capillary GC, i.e., the introduction of aqueous eluents into the GC system. The most straightforward solution is direct transfer of the eluent fraction of interest into the GC system as is done in normal-phase LC-GC[1]. This involves refocusing of the analytes by means of a retention gap or by

Correspondence to: H. Mol, Faculty of Chemical Engineering, Laboratory of Instrumental Analysis, Eindhoven University of Technology. P.O. Box 513, 5600 MB Eindhoven. Netherlands,

$\rightarrow$ Paper based on a poster presented at the 14th International Symposium on Capillary Chromatography, Baltimore. MD. May 25-29, 1992. using a PTV injector with a modified liner [2,3]. Both techniques rely on the formation of a solvent film, which in turn presupposes wettability. As water does not form a uniform solvent film on deactivated surfaces, it is not a suitable solvent for the abovementioned techniques [4]. Moreover, water has a high boiling point, requiring high solvent evaporation temperatures, and it produces a very large volume of vapour per unit volume of liquid, which seriously limits the speed of introduction into the GC system. Also, it is chemically aggressive at higher temperatures, destroying the chemically deactivated surface of precolumns. So far, there is no fully water-resistant deactivation procedure [5]. As a consequence, for direct injections of aqueous samples into the GC system, problems with adsorption of analytes in the precolumn will arise sooner or 
later. Nevertheless, the direct transfer of aqueous solvents has been used in a limited number of studies, i.e., when only small volumes are involved (packed capillary LC-GC) [6,7] and when applying concurrent solvent evaporation [8]. Furthermore, introduction of mobile phases containing water can be successful if water evaporates before the other solvent(s) as in co-solvent trapping [9] and with solvent mixtures containing an amount of water not exceeding the azeotropic composition [10].

Eliminating the aqueous solvent prior to introduction into the GC system enhances the applicability of coupled RPLC-GC. Removal of water can be done by sorption-thermal desorption and phaseswitching techniques. Pankow et al. [ 11 1] described a sorption-thermal desorption system in which water was sampled through a Tenax tube. The adsorbed analytes were thermally desorbed and introduced into the GC system after refocusing. Schomburg et al.[12] used a similar approach based on a two-oven system. More recently, the use of a PTV injector with packed liners was studied for the same purpose [13], thereby eliminating the need for two ovens. For trace analysis of organics in water, also non-coated [14,15] or coated capillaries [16-18] or entire GC columns [19-21] were used for trapping analytes from water. After thermal desorption and subsequent (cryogenic) refocusing the analytes were analysed.

In phase-switching techniques the analytes are transferred from the aqueous phase to an organic phase which is introduced into the GC system. Inspired by the promising results obtained in the field of automated sample preparation of water samples [22,23], Van Zoonen et al. [24] studied the use of on-line liquid-liquid extraction in a segmented flow system as a means of transferring the analytes from a methanol-water LC phase to an organic phase. Phase switching can also be carried out by the use of small packed trapping columns $[25,26]$. After trapping the analytes from the aqueous phase, the residual water has to be removed by drying with a flow of nitrogen. Incomplete elimination of water leads to reduced desorption efficiencies as part of the pores of the packing material are blocked by residual water. The need for a drying step can be avoided by using a desorption solvent which is (slightly) miscible with water, e.g., ethyl acetate [27], but then again small amounts of water are transferred to the GC system. Grob and Schilling [28] proposed the use of open-tubular trapping columns as an alternative to the use of packed adsorption tubes. The main advantage of the use of open-tubular traps is that complete removal of the remaining reversed-phase eluent can be obtained by simply purging a short plug of gas through the capillary. Grob and Schilling's attempts to trap analytes on a 2-m GC column were not very successful. According to the authors this was due to the low diffusion speeds in the liquid and insufficient retention power of the open-tubular trap.

The aim of this paper is to present a thorough study on the applicability of open-tubular traps as phase-switching devices for coupled RPLC-GC. A number of selected test compounds from a volume of methanol-water, which represents an average RPLC eluent, is trapped in a coated capillary. The eluent is then removed by emptying the trap by means of nitrogen prior to desorption of the analytes with hexane, which is next introduced directly into the GC system. Refocusing of theanalytes is achieved by using a PTV injector. The phase-switching process was studied in two steps. First the sorption step was studied by determining the breakthrough volumes of polycyclic aromatic hydrocarbons (PAHs) in the LC elution mode. The effects of column dimensions, flow-rate, modifier concentrations and temperature are discussed. Second, starting from $100 \%$ sorption conditions, experiments on liquid desorption were carried out. Here the effect of desorption flow-rate and length of the trapping column on the desorption volume are discussed. The applicability of the system is demonstrated by the analysis of a PAH mixture.

\section{EXPERIMENTAL}

\section{Instrumentation}

Sorption experiments were carried out using an LC system which consisted of an LC pump (LKB 2 150; Pharmacia, Woerden, Netherlands), a pulse damper (Free University, Amsterdam, Netherlands), a six-port valve with an $11-\mu 1$ loop, an open-tubular trapping column, a fluorescence detector (LS-4; Perkin-Elmer, Norwalk, CT, USA) and a recorder (BD40; Kipp \& Zonen, Delft, Netherlands). The trapping capillaries were cut from new $0.32 \mathrm{~mm}$ I.D. GC columns with either a $1.1-$ or a $5.1-\mu \mathrm{m}$ film 
of CP-Sil-5-CB (Chrompack, Bergen op Zoom, Netherlands). The valve and the trapping capillary were positioned in a thermostated water-bath. The fluoresence excitation/emission wavelength for naphthalene, phenanthrene and pyrene were 262/ $330,243 / 365$ and $236 / 392 \mathrm{~nm}$, respectively.

The phase-switching device was built around two ten-port valves (Valco, Houston, TX, USA), depicted schematically in Fig. 1. The system consisted of a sampling pump (P1) (syringe pump, type MF-2 from Azumadenki Kogyo, Japan) and a pump used for desorption (P2). This pump was a microprocessor-controlled syringe pump (Digisampler, Gerstel, Mülheim a/d Ruhr, Germany) which allowed the introduction of defined volumes of up to $1 \mathrm{ml}$ with a speed of $1-2000 \mu \mathrm{l} / \mathrm{min}$. A fraction loop of $300 \mu \mathrm{l}$ was connected between two ports of valve 1 . The open-tubular coated traps were connected between two ports of valve 2 . The nitrogen flow applied to valve 1 was controlled by a pressure regulator (adjusted to 1 bar) and a flow controller adjusted to $0.6 \mathrm{ml} / \mathrm{min}$.

A gas chromatograph (Model 5890; HewlettPackard, Avondale, PA, USA) with flame ionization detection (FID) and thermal coñductivity detection (TCD), and provided with an automated cold temperature-programmed injection system (PTV injector) (KAS 502; Gerstel) was used. For data collection a Nelson integration system (PerkinElmer) was used. The PTV injector was equipped with a liner containing a porous glass bed and a modified split vent as described elsewhere [2,3]. With this configuration low outlet pressures could be obtained, allowing high purge gas flow-rates (up to $620 \mathrm{ml} / \mathrm{min}$ ). By means of a splitter, about $1 \%$ of the purge gas is transferred to the TCD instrument for monitoring the solvent elimination.

\section{Operating conditions}

Large-volume injections. Large-volume injections werecarried out using the microprocessor-controlled syringe pump. A sample of PAHs dissolved in hexane was introduced into the PTV injector (initial temperature between -30 and $30^{\circ} \mathrm{C}$ ) at a predefined rate. The sample was introduced in the solvent split mode, applying a purge gas flow-rate of $620 \mathrm{ml} / \mathrm{min}$. When almost no solvent was left in the liner, as could be seen from the TCD signal, the GC run was started. The start of the GC run involves closing of the split valve (splitless time, $1.0 \mathrm{~min}$ ), starting the temperature programming of the column and heating the PTV injector to $275^{\circ} \mathrm{C}$ at $12^{\circ} \mathrm{C} / \mathrm{s}$. The PTV injector was kept at this temperature for $1 \mathrm{~min}$.

For the GC separations a $12.5 \mathrm{~m} \times 0.32 \mathrm{~mm}$ I.D. column coated with $0.12-\mu \mathrm{m}$ CP-Sil-5-CB was used with helium as the carrier gas at an inlet pressure of $45 \mathrm{kPa}$. The GC temperature programme was as follows: initial temperature, $40^{\circ} \mathrm{C}$ for $1 \mathrm{~min}$, then increased at $15^{\circ} \mathrm{C} / \mathrm{min}$ to $250^{\circ} \mathrm{C}$, the final temperature being held for $5 \mathrm{~min}$.

On-line phase-switching GC. The position of the valves at the start of a phase-switching cycle is shown in Fig. 1. The LC fraction loop of valve 1 is filled manually with a PAH solution in water-methanol, simulating an LC fraction. When valve 1 is switched the sample is transferred to the opentubular trap by pump 1 (containing methanolwater) and the trap is flushed with an additional $150 \mu$ l of solvent. Then valve 1 is switched back again. The nitrogen flow now slowly pushes the remaining aqueous solvent out of the trap ( $2 \mathrm{~min}$ for the 2-m trap and $4 \mathrm{~min}$ for the 5-m trap). Meanwhile pump 2 (containing hexane) is started and the transfer capillary is inserted into the PTV injector. When valve 2 is switched the analytes are desorbed from the trap and directly introduced into the PTV injector as described above for large-volume injections. Two minutes before the next sampling step valve 2 is switched back again to remove hexane remaining in the trap after desorption by the nitrogen flow. Meanwhile the sample loop is filled again, after which the next phase switching can take place.

Desorption experiments. For desorption experiments the trap was sampled using an aqueous phase containing $20 \%(\mathrm{v} / \mathrm{v})$ of methanol at a low sampling flow-rate $(28 \mu \mathrm{l} / \mathrm{min})$. For this purpose $50-\mathrm{ng} / \mathrm{ml}$ PAH solutions were used. After sorption the aqueous solvent was removed as described above. De-

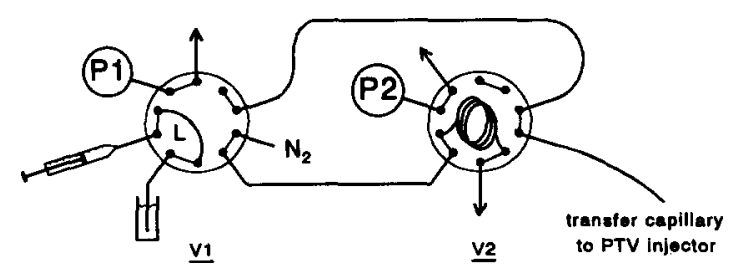

Fig. 1. Phase-switching system. V1 and V2 = valves; P1 and $\mathrm{P} 2=$ syringe pumps; $\mathrm{L}=300-\mu 1$ loop. 
sorption was then carried out applying a variety of conditions to be discussed below. Desorption profiles were obtained by repeated sampling and subsequent desorption with a stepwise increased volume of hexane. Compounds remaining in the trap were flushed to waste before the next experiment was started.

\section{THEORETICAL}

The maximum volume of sample that can be passed through an adsorption column is determined by the breakthrough volume of the solute $\left(V_{\mathrm{b}}\right)$ defined as $V_{\mathrm{r}}-3 \sigma_{\mathrm{v}}$, where $V_{\mathrm{r}}$ is the retention volume and $\sigma_{v}$ the standard deviation of the Gaussian peak eluting from the trapping column. The breakthrough volume of a component in a trapping column is given by the equation [29]

$V_{\mathbf{b}}=V_{0}(1+k)\left(1-\frac{3}{\sqrt{N}}\right)$

where $V_{0}$ is the void volume of the trapping column, $\mathbf{k}$ the capacity factor of the solute in the trap and $\mathrm{N}$ the plate number of the trapping column (with $N>9$ ).

The process of trapping analytes in an opentubular capillary is very similar to that in opentubular LC with extremely wide-bore columns. Band broadening in an open-tubular trap can therefore be described by the Golay equation:

$$
\begin{aligned}
H=\frac{2 D_{\mathrm{m}}}{u}+\frac{1+6 k+11 k^{2}}{96(k+1)^{2}} & \cdot \frac{d_{\mathrm{c}}^{2}}{D_{\mathrm{m}}} \cdot u+ \\
& \frac{2}{3} \cdot \frac{\mathrm{k}}{(k+1)^{2}} \cdot \frac{d_{\mathrm{f}}^{2}}{D_{\mathrm{s}}} u
\end{aligned}
$$

where $D_{\mathbf{m}}$ is the diffusion coefficient of the solute in the mobile phase, $u$ the linear velocity, $d_{\mathrm{c}}$ the column diameter, $d_{\mathrm{f}}$ the stationary phase thickness and $D_{\mathrm{s}}$ the diffusion coefficient of the solute in the stationary phase. The diffusion coefficients of the PAHs selected as test solutes were calculated using the modified Wilke-Chang equation [30]; the values are about $0.40 \cdot 10^{-5} \mathrm{~cm}^{2} / \mathrm{s}[25 \%$ (v/v) methanol in water at $20^{\circ} \mathrm{C}$. The diffusion coefficients of the PAHs in a polysiloxane stationary phase are cu. $10^{-7} \mathrm{~cm}^{2} / \mathrm{s}$ [31], i.e., almost two orders of magnitude lower than those in the mobile phase. As the linear velocity is far above the optimum and $d_{\mathrm{f}}$ is $5 \mu \mathrm{m}$ or less, the first and the last terms on the right-hand side of eqn. 2 can be neglected. When the capacity factor is very large, eqn. 2 reduces to

$H=\frac{11}{96} \cdot \frac{d_{\mathrm{s}}^{2}}{D_{\mathrm{m}}} \cdot u$

or, expressed in terms of the volumetric flow-rate, $F$, through the column,

$H=\frac{44}{96} \cdot \frac{\mathbf{F}}{D_{\mathrm{m}}}$

As can be seen from eqn. 4, band broadening at a constant flow-rate depends on $D_{\mathrm{m}}$ only and is independent of the column diameter. Substitution of eqn. 4 into eqn. 1 yields

$V_{\mathrm{b}}=V_{0}(1+k)\left(1-\sqrt{\frac{396 F}{96 \pi D_{\mathrm{m}} L}}\right)$

After substitution of $V_{0}$ and $k$, with $\mathbf{k}=K \beta$, where Kis the distribution constant of the analyte and $\beta$ the phase ratio given by the equation

$\beta=\frac{V_{\mathrm{m}}}{V_{\mathrm{s}}}=\frac{\left(d_{\mathrm{c}}-2 d_{\mathrm{f}}\right)^{2}}{4 d_{\mathrm{f}}\left(d_{\mathrm{c}}-d_{\mathrm{f}}\right)}$

eqn. 5 can be rewritten as

$V_{\mathrm{b}}=\frac{1}{4} \pi d_{\mathrm{c}}^{2} L\left(1+\frac{K}{\beta}\right)\left(1-\sqrt{\frac{396 F}{96 \pi D_{\mathrm{m}} L}}\right)$

Eqn. 7 shows that in order to obtain $V_{\mathrm{b}}$ values larger than zero, $\mathbf{F}$ should meet the following requirement:

$F<\frac{96 \pi}{396} \cdot D_{\mathrm{m}} L$

In the situation described so far, the breakthrough volume was defined as $V_{\mathrm{r}}-3 \sigma_{\mathrm{v}}$. Under these conditions there is a one-sided loss of only $0.15 \%$ of a Gaussian-shaped band when the sampled volume equals the breakthrough volume. For practical applications this can be considered as quantitative trapping. When higher losses are tolerated, the breakthrough volume can be redefined, which will result in higher maximum allowable flow-rates. Table I shows that when losses of 1.0 or $2.5 \%$ are accepted, the maximum sampling flow-rates can be increased by a factor 1.7 or 2.3 , respectively. For trapping analytes in a 2-m trap and with the earlier $D_{\mathrm{m}}$ value of $0.40 \cdot 10^{-5} \mathrm{~cm}^{2} / \mathrm{s}$, the maximum allow- 
TABLE I

MAXIMUM ALLOWABLE SAMPLING FLOW-RATES FOR DIFFERENT DEFINITIONS OF BREAKTHROUGH VOLUME

\begin{tabular}{|c|c|c|}
\hline Breakthrough volume & Loss $(\%)$ & $F_{\max }(\mu \mathrm{l} / \mathrm{s})^{b}$ \\
\hline $\begin{array}{l}V_{\mathrm{b}}=V_{\mathrm{r}}-3 \sigma \\
V_{\mathrm{b}}=V_{\mathrm{r}}-2.326 \sigma \\
V_{\mathrm{b}}=V_{\mathrm{r}}-1.960 \sigma \\
V_{\mathrm{b}}=V_{\mathrm{r}}-1.645 \sigma \\
V_{\mathrm{b}}=V_{\mathrm{r}}-1.28 \sigma\end{array}$ & $\begin{array}{c}0.15 \\
1.0 \\
2.5 \\
5.0 \\
10.0\end{array}$ & $\begin{array}{cc}0.762 & D_{\mathrm{m}} L \\
1.267 & D_{\mathrm{m}} L \\
1.784 & D_{\mathrm{m}} L \\
2.533 & D_{\mathrm{m}} L \\
4.184 & D_{\mathrm{m}} L\end{array}$ \\
\hline
\end{tabular}

a One-sided loss for a Gaussian-shaped band.

${ }_{b}$ Maximum allowable sampling flow-rate assuming $k=\infty$.

able sampling flow-rates corresponding to trapping efficiencies of $99.85,99.0$ and $97.5 \%$ are 37,61 and $88 \mu \mathrm{l} / \mathrm{min}$, respectively. Here, the retention power and capacity of the open-tubular trap are assumed to be sufficient. The capacity of the trap is expected to be sufficient for the relatively clean LC fractions. With direct sampling of real water samples however, overloading of the trap by other analytes or matrix components cannot be excluded.

From eqn. 7, one readily sees that larger breakthrough volumes are obtained when either $d_{\mathrm{c}}, L, K$ or $D_{\mathrm{m}}$ is increased or $\beta$ is decreased. Further, reducing the sampling flow-rate is an alternative means of increasing the breakthrough volume. Although it is evident that large trapping column dimensions $\left(d_{c}, L\right)$ are favourable for sorption, desorption puts limitations on the dimensions of the trapping column as the volume of organic solvent needed for desorption should not be too large. Too large desorption volumes will lead to a time-consuming introduction of the desorption liquid into the GC system. The effect of the other parameters on the breakthrough volume will be discussed in the next section.

\section{RESULTS AND DISCUSSION}

\section{Sorption}

Maximum allowable samplingflow-rates. The plate number of the open-tubular trap was determined to assess whether the trap meets the requirement of $N>9$ (see above). Table II shows that the experimental values are $2040 \%$ higher than the theoretical values. Apparently the $D_{\mathrm{m}}$ values are higher than
TABLE II

PLATE NUMBERS FOR NAPHTHALENE AND PHENANTHRENE IN A $2 \mathrm{~m}$ x $0.32 \mathrm{~mm}$ I.D. TRAP

Conditions: $2 \mathrm{~m}$ x $0.32 \mathrm{~mm}$ I.D. column, 1- $\mu \mathrm{m}$ CP-Sil-5-CB, methanol-water $(25: 75, \mathrm{v} / \mathrm{v}), 25^{\circ} \mathrm{C}$.

\begin{tabular}{llllll}
\hline$F(\mu 1 / \mathrm{min}) \boldsymbol{u}(\mathrm{cm} / \mathrm{s})$ & \multicolumn{2}{l}{$\begin{array}{l}\text { Naphthalene } \\
(k=4)\end{array}$} & \multicolumn{2}{l}{$\begin{array}{l}\text { Phenanthrene } \\
(k=15)\end{array}$} \\
\cline { 2 - 6 } & & $N_{\mathrm{th}}{ }^{a}$ & $N_{\mathbf{e x p}}{ }^{b}$ & $N_{\mathrm{th}}{ }^{a}$ & $N_{\mathbf{e x p}}{ }^{b}$ \\
\hline 10 & 0.21 & 61 & - & 41 & 52 \\
25 & 0.52 & 24 & 33 & 17 & 21 \\
50 & 1.04 & 12 & 15 & 8 & 10 \\
\hline
\end{tabular}

a Calculated plate numbers in methanol-water $(26: 74, \mathrm{v} / \mathrm{v})$ at $25^{\circ} \mathrm{C}$. $D_{\mathrm{m}}$ for naphthalene and phenanthrene $=0.5210^{-5}$ and $0.44 \cdot 10^{-5} \mathrm{~cm}^{2} / \mathrm{s}$, respectively.

${ }^{b}$ Plate numbers determined from elution chromatograms (injection: $11 \mu \mathrm{l}$ of 1-2 ppm PAH dissolved in the mobile phase).

calculated. In order to have $\mathrm{N}>9$, flow-rates should not exceed $50 \mu \mathrm{l} / \mathrm{min}$ for a $2-\mathrm{m}$ trap with the mobile phase used. Analyte losses due to sampling at much higher flow-rates cannot be calculated by the theory described in the previous section because the compounds then no longer elute as Gaussian-shaped bands (see Fig. 2).

Retention on the open-tubular trap. As can be seen from eqn. 1 and by comparing Fig. $2 \mathrm{~A}$ and $\mathrm{B}$, an increase in capacity factor causes a distinct increase in the breakthrough volume. The capacity factor needed for quantitative $(>\mathbf{9 9} \%$ ) trapping depends on the sampling flow-rate and the volume that has to be sampled, i.e., the volume of the LC fraction should not exceed the breakthrough volume of the trap. The LC fraction volume depends on the inside diameter of the LC column used. In this study volumes of $300 \mu \mathrm{l}$ were used, which are typical for 1-2 mm I.D. LC columns. Calculating the breakthrough volume, with $V_{0}=0.15 \mathrm{ml}, F=45 \mu \mathrm{l} / \mathrm{min}$, $L=2 \mathrm{~m}$ and $D_{\mathrm{m}}=0.52 \cdot 10^{-5} \mathrm{~cm}^{2} / \mathrm{s}$ [naphthalene in methanol-water $(26: 74, \mathrm{v} / \mathrm{v})$ at $25^{\circ} \mathrm{C}$ ], breakthrough volumes exceeding $300 \mu \mathrm{l}$ are already obtained for a $k$ value of 7 This means that naphthalene (Fig. 2A, at $45 \mu \mathrm{l} / \mathrm{min}$ ) will be trapped quantitatively under the conditions mentioned. For the example in Fig. 2B (at $45 \mu \mathrm{l} / \mathrm{min}$ ), a breakthrough volume of $800 \mu \mathrm{l}$ is achieved with $k=16$. 

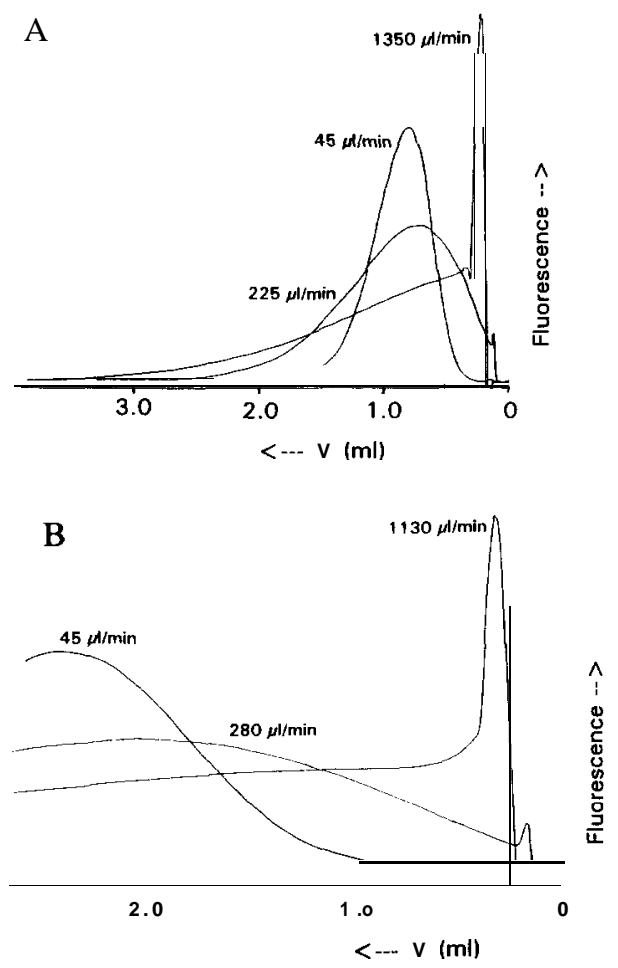

Fig. 2. Chromatograms of PAHs in an open-tubular trap. Conditions: $2 \mathrm{~m} \times 0.32 \mathrm{~mm}$ I.D. column, 5- $\mu \mathrm{m}$ CP-Sil-5-CB at $25^{\circ} \mathrm{C}$ applying different flow-rates. (A) Naphthalene $(\mathrm{k}=7.3)$. methanol-water $(30: 70, \mathrm{v} / \mathrm{v}) ;(B)$ phenanthrene $(\mathrm{k}=15.7)$. acetonitrile-water $(20: 80, \mathrm{v} / \mathrm{v})$.

If the capacity factors are too low, the retention power can be increased by working at lower organic modifier percentages. To study the influence of methanol on the sorption process, the capacity factors of the PAHs on the open-tubular trap were determined for several methanol percentages. Fig. 3 shows plots of $\log k v s$. percentage of methanol for the PAHs on $2 \mathrm{~m} \times 0.32 \mathrm{~mm}$ I.D. traps coated with a 1 - and a 5- $\mu \mathrm{m}$ film. Although these plots are not really linear over a large range of methanol percentages [32], estimated capacity factors obtained by extrapolation can be safely used to calculate breakthrough volumes. The values obtained with the $1-\mu \mathrm{m}$ film trap are low [for naphthalene $k=5$ at methanol-water $(20: 80, \mathrm{v} / \mathrm{v})]$. Therefore, a second trap was examined with a thicker film of stationary phase $(5 \mu \mathrm{m})$. The phase ratio of the $5-\mu \mathrm{m}$ trap is 14.5, which is almost five times lower than that of the $1-\mu \mathrm{m}$ trap. It was therefore expected that the capac-
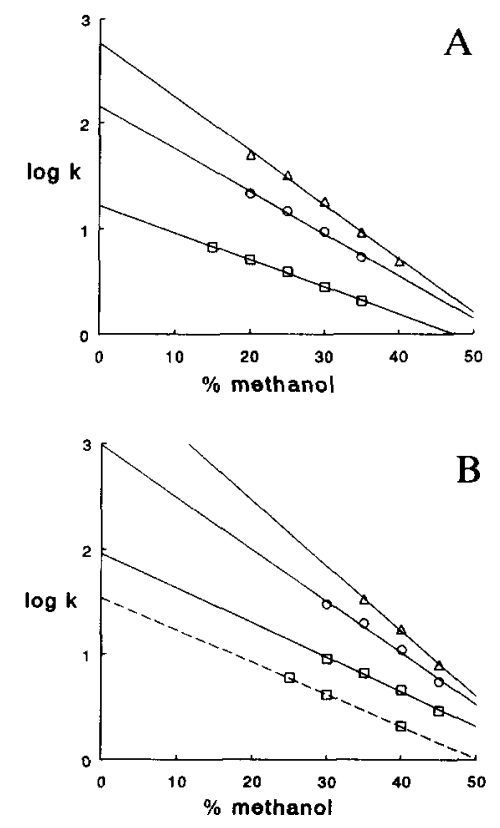

Fig. 3. Capacity factors of PAHs as a function of percentage of methanol in water at $25^{\circ} \mathrm{C}$. (A) $2 \mathrm{~m} \times 0.32 \mathrm{~mm}$ I.D. column, $1-\mu \mathrm{m}$ CP-Sil-5-CB; (B) $2 \mathrm{~m} \times 0.32 \mathrm{~mm}$ I.D. column, 5- $\mu \mathrm{m}$ CP-Sil-5-CB. $\square=$ Naphthalene (dashed line, temperature $60^{\circ} \mathrm{C}$ ); $0=$ phenanthrene; $\triangle=$ pyrene.

ity factors would increase by a factor of live. The experimental capacity factors, however, increased only 3.5 -fold. With the $5-\mu \mathrm{m}$ film trap phenanthrene and pyrene can be trapped from up to $35-40 \%$ methanol in water mobile phases $(k>16)$.

A higher retention power can be achieved by using traps with still lower phase ratios, i.e., with very thick films such as are used for trapping analytes from headspace samples [33,34]. With hexane as the desorption liquid, uptake of the desorption liquid into the stationary phase can cause a significant swelling, which results in an increased film thickness. As the hexane remaining in the trap after desorption is not removed until just before the next sorption, a swollen phase will be created in each cycle. A tremendous phase swelling was observed for the 5- $\mu \mathrm{m}$ film: the internal volume of the trap decreased from 154 to $104 \mu \mathrm{l}$ after flushing with hexane. If the retained $50 \mu \mathrm{l}$ of hexane form a uniform film in the trap, this means that the film thickness increases from 5 to about $30 \mu \mathrm{m}$, and the phase ratio now is a mere 1.2. The nature of the 
stationary phase also changes, and capacity factors were found to increase strongly. In the swollen phase they were 15-20-fold higher than in the original $5-\mu \mathrm{m}$ film trap. It should now be possible to trap phenanthrene and pyrene from $65 \%(\mathrm{v} / \mathrm{v})$ and naphthalene from $55 \%(\mathrm{v} / \mathrm{v})$ methanol in water $(k>16)$.

As hexane is slightly soluble in methanol-water mixtures, the mobile phase will strip the hexane from the stationary phase. Fig. 4 shows the decrease in retention power of the trap after the passage of various methanol-water mixtures. For methanolwater $(60: 40, \mathrm{v} / \mathrm{v})$, there is essentially no decrease. For sample volumes not exceeding $1 \mathrm{ml}$, even $70-75 \%(v / v)$ methanol in water mixtures can be used without severe effects on $k$ caused by stripping of the hexane, as the swollen film will be restored prior to the next run, viz., during desorption.

Effect of temperature on sorption. The breakthrough volume is affected by the temperature via the diffusion coefficient of the analytes in the mobile phase and via the capacity factor. Theoretically, $D_{\mathrm{m}}$ values will increase with a factor of about 2.5 on increasing the temperature from 25 to $60^{\circ} \mathrm{C}$, thereby allowing for higher sampling flow-rates (eqn. 8). The capacity factors of the PAHs were found to decrease by a factor of 2.2-3.4 (for an example, see the dashed line in Fig. 3). As in most instances retention power is expected to be more critical than sampling flowrates, trapping of the analytes at room temperature

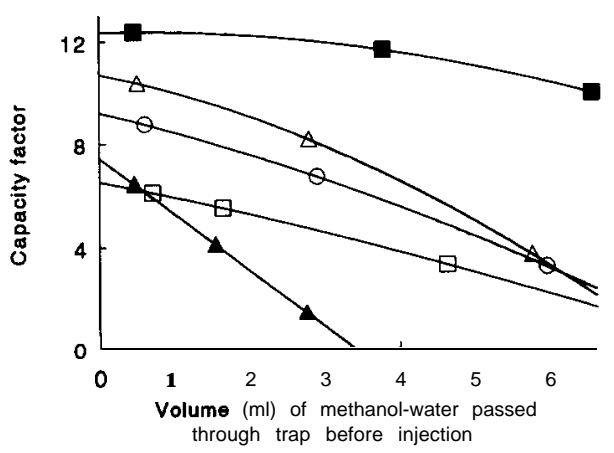

Fig. 4. Decrease in capacity factors due to stripping of hexane from a swollen stationary phase by methanol-water mixtures. Conditions: $2 \mathrm{~m}$ x $0.32 \mathrm{~mm}$ I.D. column, 5- $\mu \mathrm{m}$ CP-Sil-5-CB swollen by rinsing with hexane; flow-rate, $45 \mu \mathrm{l} / \mathrm{min}$; temperature, $25^{\circ} \mathrm{C}$. = Naphthalene [methanol-water $\left.(60: 40, \mathrm{v} / \mathrm{v})\right] ; \square=$ naphthalene; $0=$ phenanthrene; $\Delta=$ pyrene [all three in methanol-water $(70: 30, \mathrm{v} / \mathrm{v})] ; \mathrm{A}=$ pyrene [methanol-water $(80: 20$, $\mathrm{v} / \mathrm{v})]$ is generally preferable over trapping at elevated temperatures.

Stability of trap. An important practical aspect of the use of open-tubular traps for phase-switching is the stability of the stationary phase on flushing with large volumes of water-methanol and hexane. To this end, capacity factors were again determined after 5 months of continuous usage ( $\mathrm{ca} .600 \mathrm{ml}$ of methanol-water passed through the trap). The decreases in the capacity factors were found to vary between 20\% (naphthalene) and 33\% (pyrene) and are no doubt merely due to degradation and dissolution of the stationary phase. From this it can be concluded that the solvent resistance of the trap is sufficient to ensure trouble-free use for many hundreds of phase-switchings.

\section{Elimination of the aqueous phase}

The aqueous phase was removed from the trap with a nitrogen flow-rate of $0.6 \mathrm{ml} / \mathrm{min}$. Removal was carried out slowly (during $2 \mathrm{~min}$ ) to prevent possible breaking up of the aqueous plug. No additional drying with nitrogen was performed, i.e., introduction of hexane was started immediately after completion of the solvent removal. Hexane leaving the trap was transferred directly to the GC system. Elimination of the aqueous phase appears to be satisfactory as there was no indication (irregular solvent peak, peak shape of the solutes) that water entered the GC system. Chromatograms obtained after phase-switching were not different from those obtained on splitless injection of a hexane solution. A more detailed study using (more polar) analytes sensitive to adsorption or decomposition on active surfaces in the PTV liner or column is, however, necessary to evaluate whether water is really completely removed.

\section{Desorption and introduction into the GC system}

After sorption and elimination of water the analytes are desorbed with hexane, which is introduced directly into the GC system. As the desorption volume is relatively large, refocusing of the solutes is necessary. This is done by selective solvent elimination in a PTV injector. Both liquid desorption from the trap and solvent elimination in the PTV injector can affect the recovery of the analytes. The occurrence of losses during solvent elimination in the PTV injector was studied by performing large-volume 
injections of PAHs dissolved in hexane. Next the combined desorption-solvent elimination process was examined. Low sorption flow-rates and low concentrations of modifier were used to ensure quantitative trapping of the PAHs during sorption.

Large-volume injections using a PTV injector. The PTV injector is equipped with a liner containing a deactivated porous glass bed. The PTV injector can be cooled for retaining volatile components more efficiently. The solvent introduction rate depends on the initial PTV temperature. Data on optimum introduction speeds have been published previously $[2,3]$. The initial PTV temperature and the volume injected can both affect the recovery of the solutes after solvent elimination. The effects of initial PTV temperature and injected volume on recovery of three PAHs are shown in Fig. 5. With the volatile naphthalene, even on cooling the PTV to $-28^{\circ} \mathrm{C}$ (introduction rate applied at this temperature $25 \mu \mathrm{l}$ / min) significant losses were observed when more than $50 \mu \mathrm{l}$ of the hexane solution were introduced. For the other PAHs solvent elimination was not so critical. Phenanthrene is still quantitatively recovered at an initial PTV temperature of $30^{\circ} \mathrm{C}$ (introduction rate $250 \mu \mathrm{l} / \mathrm{min}$ ), provided that the volumes are not too large. An initial temperature of $-10^{\circ} \mathrm{C}$ (introduction rate $50 \mu \mathrm{l} / \mathrm{min}$ ) would offer a good compromise with regard to introduction time and recovery for naphthalene.

Desorption of PAHs with hexane. Two aspects are of major interest where desorption is concerned: desorption speed and desorption volume needed for

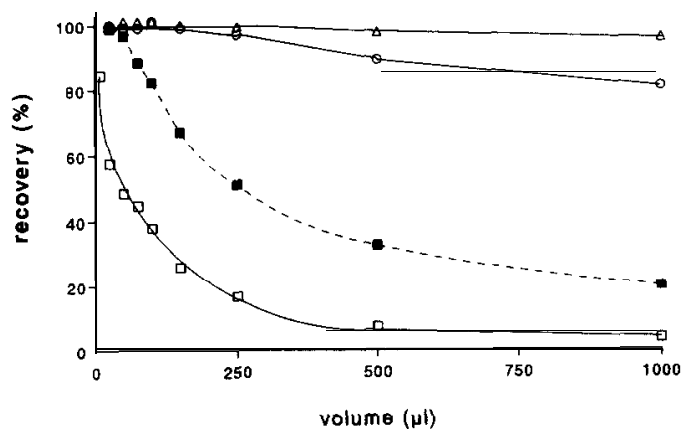

Fig. 5. Effect of initial PTV temperature and volume introduced on recovery for large-volume injections of PAHs in hexane. - = Naphthalene (PTV temperature $-28^{\circ} \mathrm{C}$. introduction speed $25 \mu \mathrm{l} / \mathrm{min}) ; \square=$ naphthalene; $0=$ phenanthrene; $\triangle=$ pyrene (PTV temperature $30^{\circ} \mathrm{C}$, introduction speed $250 \mu \mathrm{l} / \mathrm{min}$ ). quantitative recovery of the analytes from the trap. These two aspects are interrelated. Desorption of the analytes with hexane is a chromatographic process. The volume needed for desorption depends on the chromatographic band broadening during desorption, which can be described similarly to broadening during sorption. Instead of a breakthrough volume which corresponds to the start of an eluting peak, a desorption volume $\left(V_{\mathrm{d}}\right)$ corresponding to the end of an eluting peak now has to be used. Here $V_{d}=$ $V_{\mathrm{r}}+3 \sigma_{\mathrm{v}}$ or $(c f .$, eqn. 1$)$,

$V_{\mathrm{d}}=V_{0}(k+1)\left(1+\frac{3}{\sqrt{N}}\right)$

Because the trap is empty when desorption starts. the volume of liquid leaving the trap will be $V_{\mathrm{d}}^{\prime}=$ $V_{\mathrm{d}}-V_{0}$. Small desorption volumes are obtained if the void volume and the capacity factor are small and the plate number is large. The need for a small void volume in order to obtain small desorption volumes is in contradiction with the demand for a large void volume in order to create efficient sorption. This means that, especially with regard to the column diameter, a compromise has to be made in order to keep the desorption volume at an acceptable level.

The contribution of chromatographic band broadening to $V_{\mathrm{d}}$ cannot be determined reliably because accurate values for the diffusion coefficients of the analytes in the swollen stationary phase are not available. However, once the values for $k$ and $V_{\mathrm{d}}$ for the desorption of an analyte from a trap (length $L_{1}$ ) have been experimentally determined (see below), it is possible to calculate the volume needed for desorption of that component from a similar trap of different length $\left(L_{2}\right)$. The following equation for the unknown desorption volume $V_{\mathrm{d}_{2}}$ can be derived:

$V_{\mathrm{d}_{2}}=V_{0_{1}}(1+k)\left(\frac{L_{2}}{L_{1}}-\sqrt{\frac{L_{2}}{L_{1}}}\right)+\sqrt{\frac{L_{2}}{L_{1}}} \cdot V_{\mathbf{d}_{1}}$

As regards the capacity factors, their values are determined by the distribution constant $(\mathrm{K})$ and the phase ratio. During desorption the analytes partition between two very similar phases, a silicone phase strongly swollen by hexane (stationary phase) and hexane (mobile phase). It can therefore be expected that $K$ will have a value of $c a$. 1 . With the known phase ratio of 1.2 , the expected capacity 
factor of the PAHs during desorption is then about 0.8 . Experimental values of capacity factors can be estimated from the desorption curves in Fig. 6. The desorption volume corresponding to $50 \%$ recovery is the adjusted retention volume $\left(V_{\mathrm{r}}^{\prime}\right)$ of the PAHs. Introduction of the known void volume yields experimental capacity factors of about 0.45. Apperently the PAHs have a slight preference for the pure hexane phase; $K=0.54$.

The desorption volumes are dependent on the desorption speed (see above). This was experimentally verified by desorbing the analytes at different flow-rates. The initial band width was assumed to be relatively small because a low flow-rate was used for sorption. The desorption profiles for two traps obtained at different desorption flow-rates are shown in Fig. 6. The higher the desorption flow-rate, the stronger is the band broadening and the larger the volume needed for complete desorption. Using the 2-m trap and applying desorption flow-rates of 10 , 50 and $250 \mu \mathrm{l} / \mathrm{min}$, the desorption volumes $\left(V_{\mathrm{d}}^{\prime}\right)$ ( $>99 \%$ recovery) were 70,80 and $125 \mu \mathrm{l}$, respectively. Knowing the capacity factors and the desorption volumes for the PAHs in the 2-m trap, the desorption volumes for longer traps can be calculated. The results are given in Table III. Calculated and measured $V_{\mathbf{d}}^{\prime}$ values for the 5-m trap are seen to match well.

As far as desorption is concerned, the maximum length of trapping column that can be used depends on the application. For volatile analytes short

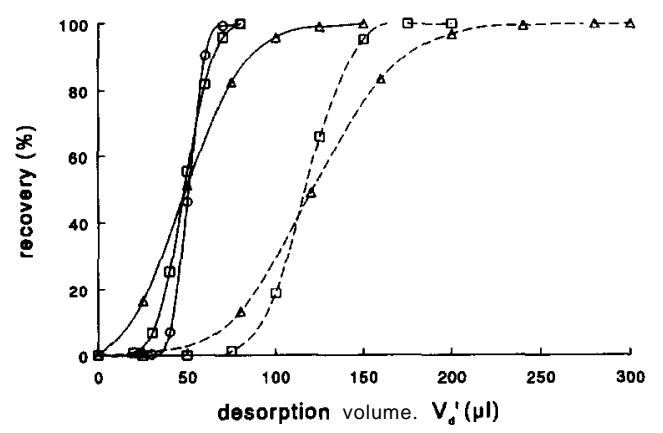

Fig. 6. Effect of desorption flow-rate (hexane) on the desorption profile. Flow-rate: $0=10 ; \square=50 ; \triangle=250 \mu \mathrm{l} / \mathrm{min}$. Trap: $0.32 \mathrm{~mm}$ I.D., $5-\mu \mathrm{m}$ film; solid line, $2 \mathrm{~m}$; dashed line, $5 \mathrm{~m}$. Sample: $300 \mu \mathrm{l}$ of $50 \mathrm{ppb}$ pyrene in methanol-water $(20: 80, \mathrm{v} / \mathrm{v})$; sorption flow-rate, $28 \mu \mathrm{l} / \mathrm{min}$.
TABLE III

EFFECT OF DESORPTION FLOW-RATE AND TRAP LENGTH ON DESORPTION VOLUMES

\begin{tabular}{|c|c|c|c|c|c|}
\hline \multirow[t]{3}{*}{$F(\mu 1 / \min )$} & \multicolumn{5}{|c|}{ Desorption volume", $V_{\mathrm{d}}^{\prime}(\mu \mathrm{l})$} \\
\hline & \multicolumn{2}{|c|}{ Experimental" } & \multicolumn{2}{|c|}{ Calculated' } & \multirow[b]{2}{*}{$25 \mathrm{~m}$} \\
\hline & $2 \mathrm{~m}$ & $5 \mathrm{~m}$ & $5 \mathrm{~m}$ & $10 \mathrm{~m}$ & \\
\hline 10 & 60 & & 140 & 260 & 625 \\
\hline 50 & 70 & 150 & 150 & 280 & 650 \\
\hline 250 & 95 & 190 & 195 & 340 & 750 \\
\hline
\end{tabular}

trapping columns are preferable, for two reasons. First, the desorption volume should be small in order to obtain high recoveries in the solvent elimination step (Fig. 5). Second, short trapping columns yield acceptable desorption time. Volatile analytes require a low PTV temperature, which in turn necessitates a low introduction speed. The volume of desorption liquid needed to transfer the analytes from the trap to the PTV is equal to $V_{\mathrm{d}}=V_{0}+V_{\mathrm{d}}^{\prime}$ (the actual volume introduced is $V_{\mathrm{d}}^{\prime}$ ). For example, with a PTV temperature of $-30^{\circ} \mathrm{C}$ corresponding to a desorption speed of $25 \mu \mathrm{l} / \mathrm{min}$, desorption from a 10-m trap (swollen phase) would take about $32 \mathrm{~min}$. For less volatile analytes, on the other hand, the use of a 10-m trap is fully acceptable. For a high-boiling analyte, such as pyrene, even a 25-m trapping column can be used with quantitative desorption and analyte recovery after solvent elimination within $8.5 \mathrm{~min}$. Such long trapping columns are, of course, very favourable from the sorption point of view.

Quantitative aspects of on-line phase-switching GC

After completion of the sorption experiments in the LC mode and the desorption experiments, the effect of sampling flow-rate and modifier concentration on the overall recovery in on-line phase-switching GC was studied. Here the $2 \mathrm{~m} \times 0.32 \mathrm{~mm}$ I.D. trapping column coated with a $5-\mu \mathrm{m}$ film was used. The volume of aqueous sample with which phase switching was carried out was $300 \mu \mathrm{l}$, which is a typical value for LC peak volumes eluting from 
1-2 mm I.D. columns. Phase switching of larger volumes should be possible by taking longer trapping capillaries. Sampling was followed by flushing the trap with $150 \mu$ l of methanol-water, which may be necessary in future applications to remove buffer salts.

The effect of the sampling flow-rate on the recovery is shown in Table IV. In this example losses can be caused only by too high sampling rates, because the conditions were such that breakthrough caused by insufficient analyte retention and losses during desorption and solvent elimination in the PTV injector were excluded. In accordance with the predictions of Lövkvist et al. [35], the experimental recoveries were higher than those expected assuming Gaussian elution profiles. In other words, with a $2 \mathrm{~m} \times 0.32 \mathrm{~mm}$ I.D. trap at room temperature, a flow-rate of $100 \mu \mathrm{l} / \mathrm{min}$ can be used without loss of analytes due to incomplete trapping. This flow-rate results in an acceptable sorption time of $4.5 \mathrm{~min}$ for the sample described.

The effect of the methanol percentage on recovery (applying a relatively high sorption flow-rate of $111 \mu \mathrm{l} / \mathrm{min}$ ) is given in Table V. Under the applied PTV and desorption conditions naphthalene is partially lost during solvent elimination in the PTV. At a methanol concentration of $80 \%(\mathrm{v} / \mathrm{v})$, losses due to insufficient retention power of the trap are

\section{TABLE IV}

RECOVERY OF PYRENE AT DIFFERENT SORPTION FLOW-RATES

\begin{tabular}{cll}
\hline $\boldsymbol{F}(\mu \mathrm{l} / \mathrm{min})$ & \multicolumn{2}{l}{ Recovery $(\%)$} \\
\cline { 2 - 3 } & Theoretical” & Experimental $^{b}$ \\
\hline 14 & 100 & 100 \\
28 & 100 & 100 \\
42 & 100 & 100 \\
111 & 95 & 99 \\
333 & 83 & 91 \\
1000 & 71 & 81 \\
2000 & 65 & 71 \\
\hline
\end{tabular}

a Based on Gaussian elution profile; $D_{\mathrm{m}}$ of pyrene $=0.37$ $10^{-5} \mathrm{~cm}^{2} / \mathrm{s}$

${ }^{b}$ Conditions: trap, $2 \mathrm{~m} \times 0.32 \mathrm{~mm}$ I.D., 5- $\mu \mathrm{m}$ CP-Sil-5-CB; mobile phase, methanol-water $(20: 80, \mathrm{v} / \mathrm{v})$; temperature, $20^{\circ} \mathrm{C}$. Sample, $300 \mu \mathrm{l}$ of $37 \mathrm{ppb}$ pyrene. Desorption with $80 \mu \mathrm{l}$ of hexane at $50 \mu \mathrm{l} / \mathrm{min}$; PTV initial temperature, $-10^{\circ} \mathrm{C}$.
TABLE V

EFFECT OF METHANOL CONCENTRATION IN WATER ON RECOVERY IN ON-LINE PHASE-SWITCHING GC

Trap, $2 \mathrm{~m} \times 0.32 \mathrm{~mm}$ I.D., $5-\mu \mathrm{m}$ film. Sample, $300 \mu \mathrm{l}$ of $40-50 \mathrm{ppb}$ PAH solution sampled at $111 \mu \mathrm{l} / \mathrm{min}$. Desorption. $85 \mu \mathrm{l}$ of hexane at $50 \mu \mathrm{l} / \mathrm{min}$. PTV initial temperature, $-10^{\circ} \mathrm{C}$.

\begin{tabular}{lllr}
\hline $\begin{array}{l}\text { Methanol in water } \\
(\%, v / v)\end{array}$ & Recovery $(\%)$ & \\
\cline { 2 - 4 } & Naphthalene & Phenanthrene & Pyrene \\
\hline 20 & 69 & 101 & 102 \\
50 & 66 & 100 & 99 \\
65 & 61 & 100 & 97 \\
80 & 34 & 82 & 90 \\
\hline
\end{tabular}

observed for all analytes. The repeatability of the total phase-switching-solvent elimination process was found to be very good. The relative standard deviation (R.S.D.) was $2.5 \%(n=3)$ or less both when the analyte recovery was quantitative and when losses occurred.

As an example, Fig. 7 shows he separation of

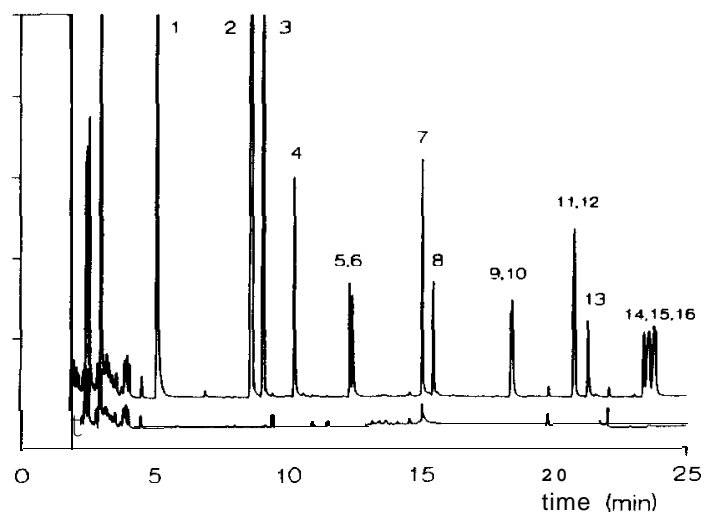

Fig. 7. On-line phase-switching GC of sixteen PAHs and a system blank (methanol-water). Sample. $300 \mu \mathrm{l}$ of a solution of sixteen PAHs in methanol-water $(50: 50, \mathrm{v} / \mathrm{v})$; concentrations, 200 $400 \mathrm{ppb}(\mathrm{l}-3)$ and $20-40 \mathrm{ppb}$ (4-16). Sampling flow-rate, $111 \mu \mathrm{l} / \mathrm{min}$. Trap: $2 \mathrm{~m} \times 0.32 \mathrm{~mm}$ I.D., 5- $\mu \mathrm{m}$ film (swollen with hexane). Desorption, $80 \mu \mathrm{l}$ of hexane at $25 \mu \mathrm{l} / \mathrm{min}$. PTV initial temperature, $-30^{\circ} \mathrm{C}$. GC temperature programme, $40^{\circ} \mathrm{C}$ ( $2 \mathrm{~min}) \rightarrow 10^{\circ} \mathrm{C} / \mathrm{min} \rightarrow 275^{\circ} \mathrm{C}$. Recoveries: (1) naphthalene, $80 \%$; (2) acenaphtylene, 98\%; (3) acenaphtene, 97\%; (4) tluorene, 99\%; (5) phenanthrene, 100\%; (6) anthracene, 97\%; (7) fluoranthene, 102\%; (8) pyrene, 99\%; (9.10) benzo[a]anthracene + chrysene $(97 \%)$; $(1 \mathrm{I}, 12)$ benzo[b]fluoranthene + benzo[ $k]$ fluoranthene, 93\%; (13) benzo[a]pyrene, 92\%; (14) indeno[1,2,3-cd]pyrene, $88 \%$; (15) dibenzo[ $a, h]$ anthracene, $85 \%$; (16) benzo $[g h i]$ perylene. $86 \%$. 
sixteen PAHs after phase switching from methanol-water $(50: 50, \mathrm{v} / \mathrm{v})$ to hexane. Data on recoveries (SO-102\%) are given in the caption.

\section{CONCLUSIONS}

Theory allows the influence of various operating conditions, such as flow-rate, column dimensions and diffusion coefficients, on the phase-switching process to be described. In order to trap analytes quantitatively the sampling flow-rates should not exceed a certain maximum value which depends only on the diffusion coefficient of the analyte in the aqueous phase and the length of the trapping column. For a $2 \mathrm{~m} \times 0.32 \mathrm{~mm}$ I.D. trap, the maximum sampling flow-rate was found to be $c a$. $100 \mu \mathrm{l} / \mathrm{min}$. For trapping analytes from conventional LC eluents, i.e., eluents containing high percentages of modifier, the phase ratio of the trap should be very low, i.e., thick films have to be used. Stationary phase swelling due to the uptake of large amounts of desorption fluid (hexane) into the stationary phase leads to a substantial increase in the film thickness and hence the retentive strength of the trap. The retention power in a thick-film trap with a swollen stationary phase is found to be sufficient to trap PAHs from 300- $\mu$ l LC fractions containing up to $65 \%(\mathrm{v} / \mathrm{v})$ methanol. Elimination of the aqueous phase from the trap is easily performed by briefly purging with nitrogen. The volume of hexane needed for desorption of the trapped analytes can easily be handled by PTV injection devices. Using these devices solvent elimination is rapid and loss of analytes can be avoided.

It can be concluded that open-tubular traps are highly promising for phase-switching in coupled RPLC-GC. The system described here also holds promise for automated pretreatment of aqueous samples.

\section{ACKNOWLEDGEMENT}

The Foundation for Chemical Research in the Netherlands (SON) is gratefully acknowledged for their financial support.

\section{REFERENCES}

I K. Grob (Editor), O n-Line Coupled LC-G C, Hiithig, Heidelberg, 1991.

2 J. Staniewski and J. A. Rijks, J. Chromatogr., 623 (1992) 105-I 13.

3 J. Staniewski and J. A. Rijks, in P. Sandra (Editor), Proceedings of the 13th Symposium on Capillary Chromatography, Riva del Garda, Italy, 1991, Hiithig, Heidelberg, 1991, pp. 13341347.

4 K. Grob, J. Chromatogr., 473 (1989) 381-390.

5 K. Grob and A. Artho, J. High Resolut. Chromatogr., 14 (1991) 212-214.

6 H. J. Cortes, C. D. Pfeiffer, G. J. Jewett and B. E. Richter, J. Microcol. Sep., 1 (1989) 28-34.

7 D. Duquet, C. Dewaele, M. Verzele and S. McKinley, J. High Resolut. Chromatogr., 11 (1988) 824-829.

8 K. Grob and Z. Li, J. Chromatogr., 473 (1989) 423430.

9 K. Grob, J. Chromatogr., 477 (1989) 73-86.

10 E. C. Goosens, D. de Jong, J. H. M. van den Berg, G. J. de Jong and U. A. Th. Brinkman, J. Chromatogr., 552 (1991) 489-500.

11 J. F. Pankow, L. M. Isabelle and T. J. Kristensen, A nal. Chem., 54 (1982) 1815-1819.

12 G. Schomburg, E. Bastian, H. Behlau, H. Husmann, F. Weeke, M. Oreans and F. Miiller, J. High Resolut. Chromatogr. Chromatogr. Commun., 7 (1984) 4-12.

13 J. J. Vreuls, U. A. Th. Brinkman, G. J. de Jong, K. Grob and A. Artho, J. High Resolut. Chromatogr., 14 (1991) 455459.

14 A. Zlatkis, R. P. J. Ranatunga and B. S. Middleditch, Anal. Chem., 62 (1990) 2471-2478.

15 A. Zlatkis, R. P. J. Ranatunga and B. S. Middleditch, Chromatographia, 29 (1990) 523-529.

16 D. A. M. MacKay and M. M. Hussein, J. Chromatogr., 176 (1979) 291-303.

17 M. M. Hussein and D. A. M. MacKay, J. Chromatogr., 243 (1982) 43-50.

18 S. Blomberg and J. Roeraade, J. High Resolut. Chromatogr., 13 (1990) 509-512.

19 A. Zlatkis, F.-S. Wang and H. Shanfield, Anal. Chem., 55 (1983) 1848-1852.

20 R. E. Kaiser and R. Rieder, J. Chromafogr., 477 (1989) 49-52.

21 G. Goretti, M. V. Russo and E. Veschetti, J. High Resolut. Chromatogr., 15 (1992) 51-54.

22 J. Roeraade, J. Chromatogr., 330 (1985) 263-274.

23 E. Fogelquist, M. Krysell and L. G. Danielson, Anal. Chem., 58 (1986) 15161520.

24 P. van Zoonen, G. R. van der Hoff and E. A. Hogendoorn, J. High Resolut. Chromatogr., 13 (1990) 483-488.

25 E. Noroozian, F. A. Maris, M. W. F. Nielen, R. W. Frei, G. J. de Jong and U. A. Th. Brinkman, J. High Resolut. Chromatogr. Chromatogr. Commun., 10 (1987) 17-20.

26 Th. Noy, E. Weiss, T. Herps, H. van Cruchten and J. Rijks, J. High Resolut. Chromatogr. Chromatogr. Commun., 11 (1988) 181-186.

27 J. J. Vreuls, V. P. Goudriaan, U. A. Th. Brinkman and G. J. de Jong, J. High R esolut. Chromatogr., 14 (1991) 475-480.

28 K. Grob and B. Schilling, J. High Resolut. Chromatogr. Chromatogr. Commun., 8 (1985) 126733. 
29 C. E. Werkhoven-Goewie, U. A. Th. Brinkman and R. W. Frei, Anal. Chem., 53 (1981) 2072-2080.

30 R. C. Reid, J. M. Prausnitz and T. K. Sherwood (Editors), The Properties of Gases and Liquids, McGraw-Hill, London. 1977.

31 0. van Berkel, H. Poppe and J. C. Kraak, Chromatographia, 24 (1987) 739-744.
32 P. J. Schoenmakers, H. A. H. Billiet and L. de Galan, J. Chromatogr., 185 (1979) 179-195.

33 S. Blomberg and J. Roeraade, J. High Resolut.Chromatogr., 13 (1990) 509-512.

34 B. V. Burger, M. le Roux, Z. M. Munro and M. E. Wilka. J. Chromatogr.. 52 (1991) 137-151

35 P. Lövkvist and J. §. Jönsson. Anal. Chrm., 59 (1987) 818-821. 